Dedicated to the American Aviation Corps

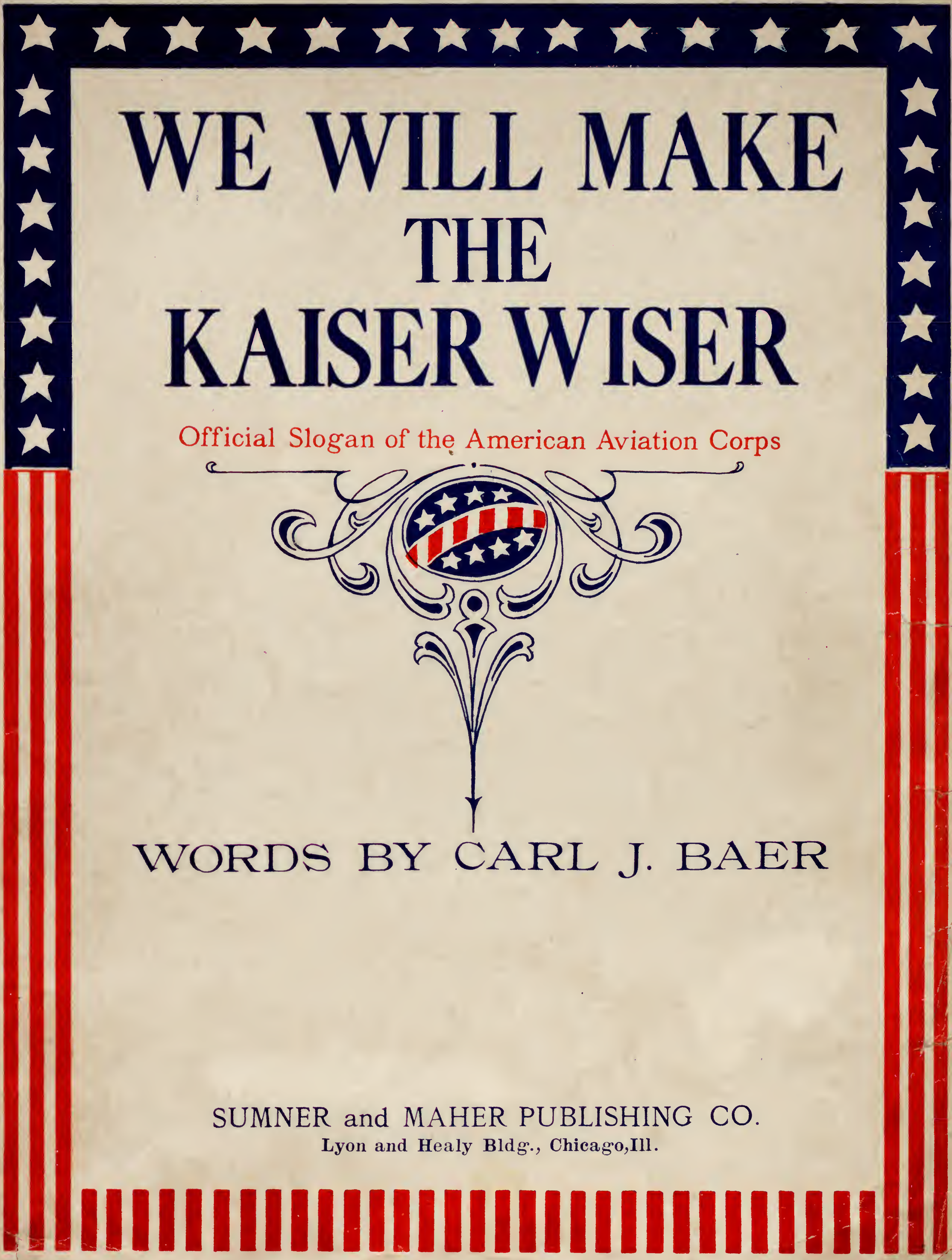




\section{We Will Make The Kaiser Wiser WAR SONG}

Tune: BATTLE HYMN OF THE REPUBLIC (John Brown's Body) Words by
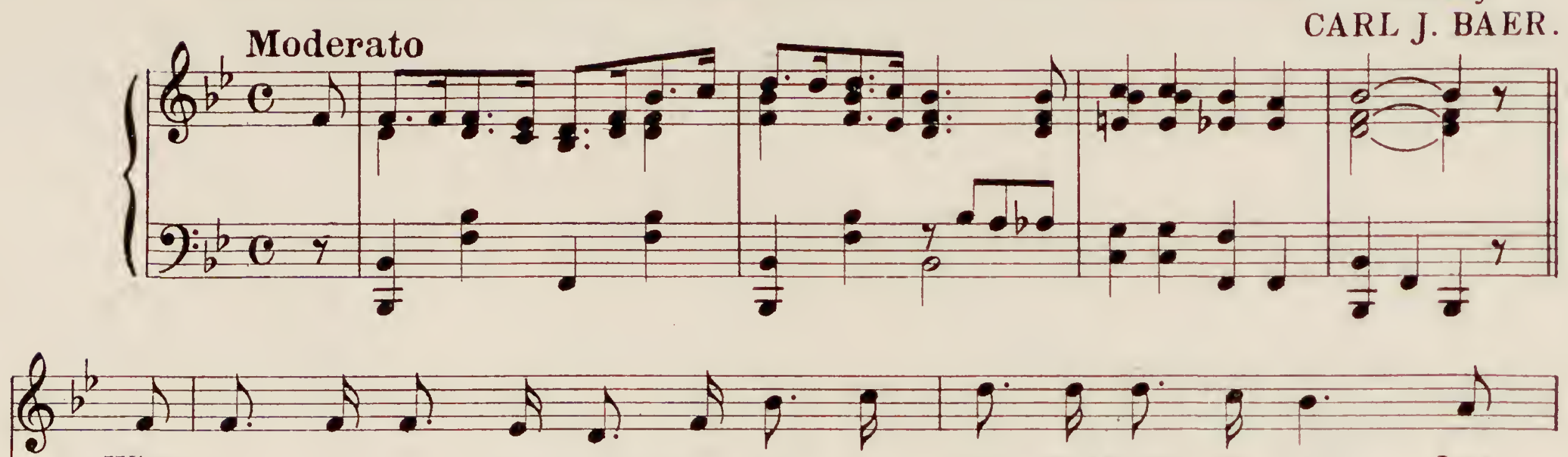

When - ev - er in the world you find a man who knows it al1; Just

He made his plans to get the earth and all the peo-ple too, He
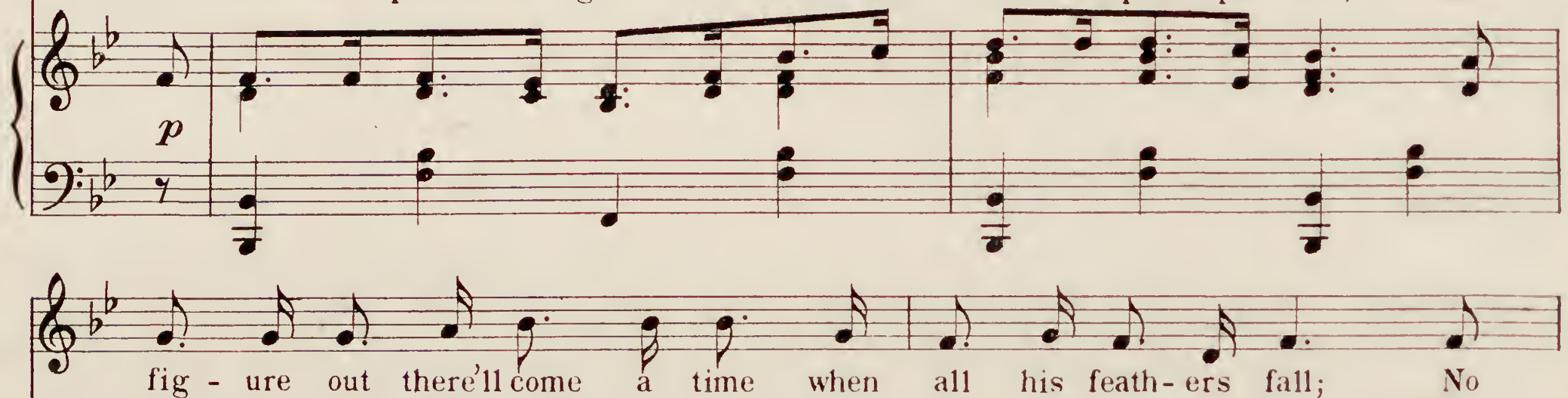

$\begin{array}{lllllll}\text { fig - ure out there'1l come a time when all his feath-ers fall; } & \text { No } \\ \text { start-ed work just af - ter birth, to Cop it for a few, } & \text { But }\end{array}$
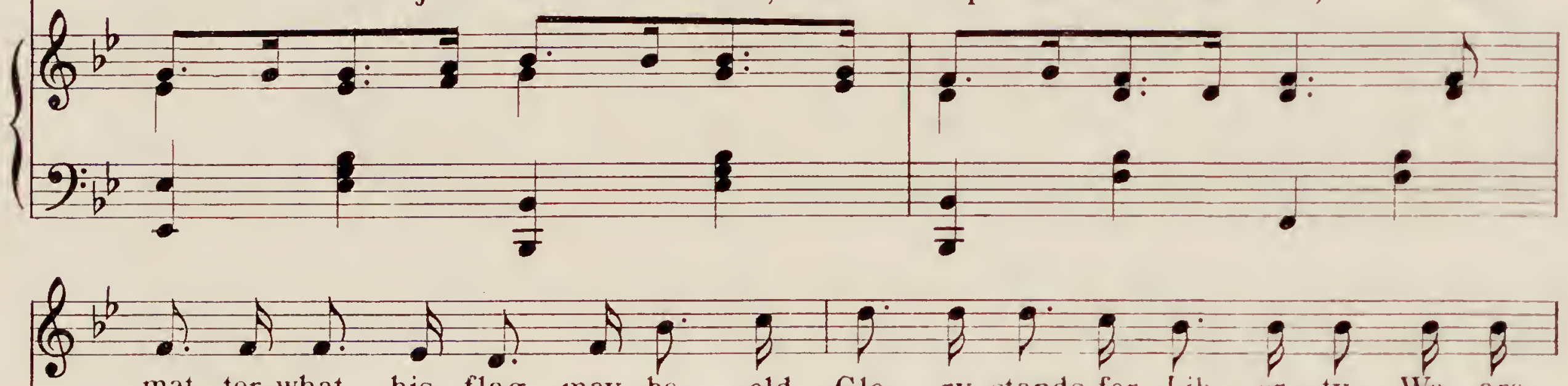
mat-ter what his flag may be old Glo ry stands for Lib - er-ty, We are when he spread be-yond the sea, he touched the heart of you and me It's
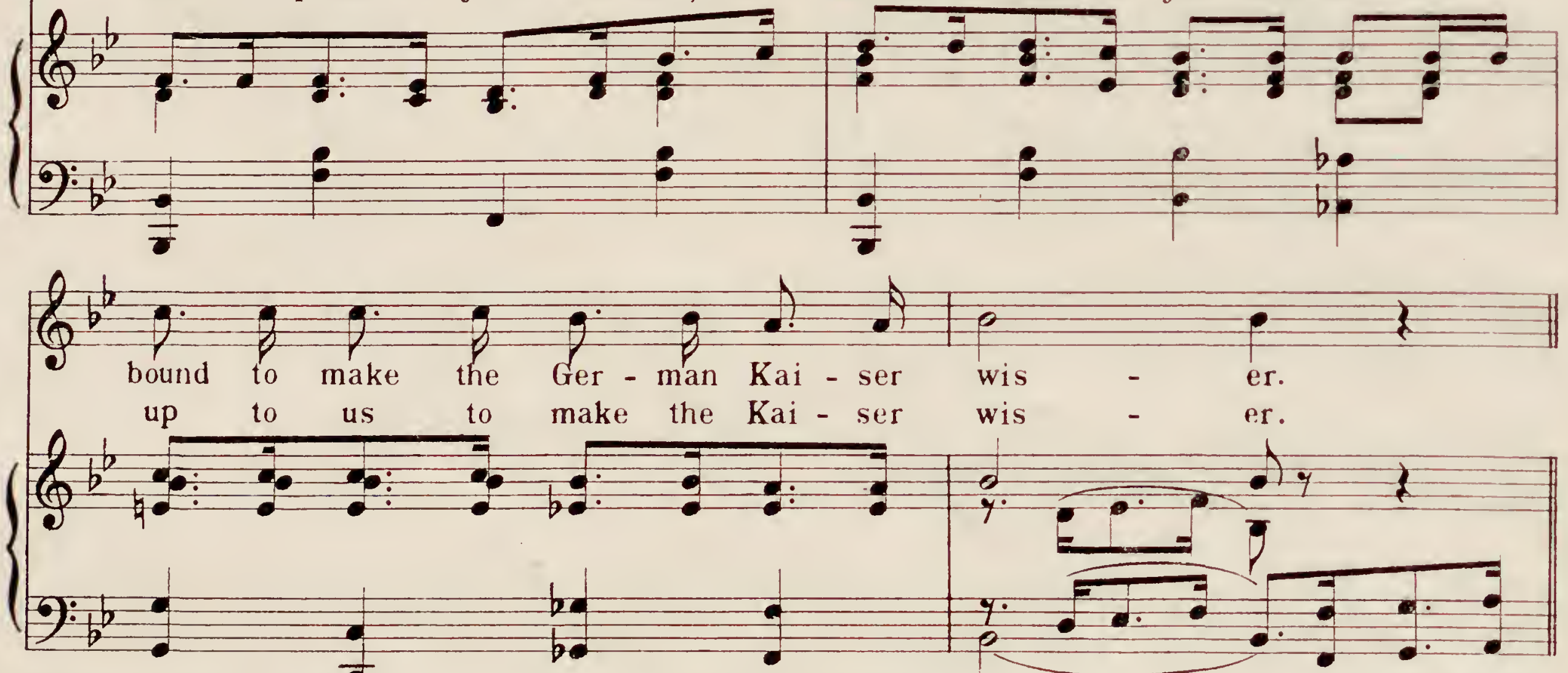

International Copyright Secured. Copyright MCMXVII by Carl J. Baer.

All Rights Reserved. 


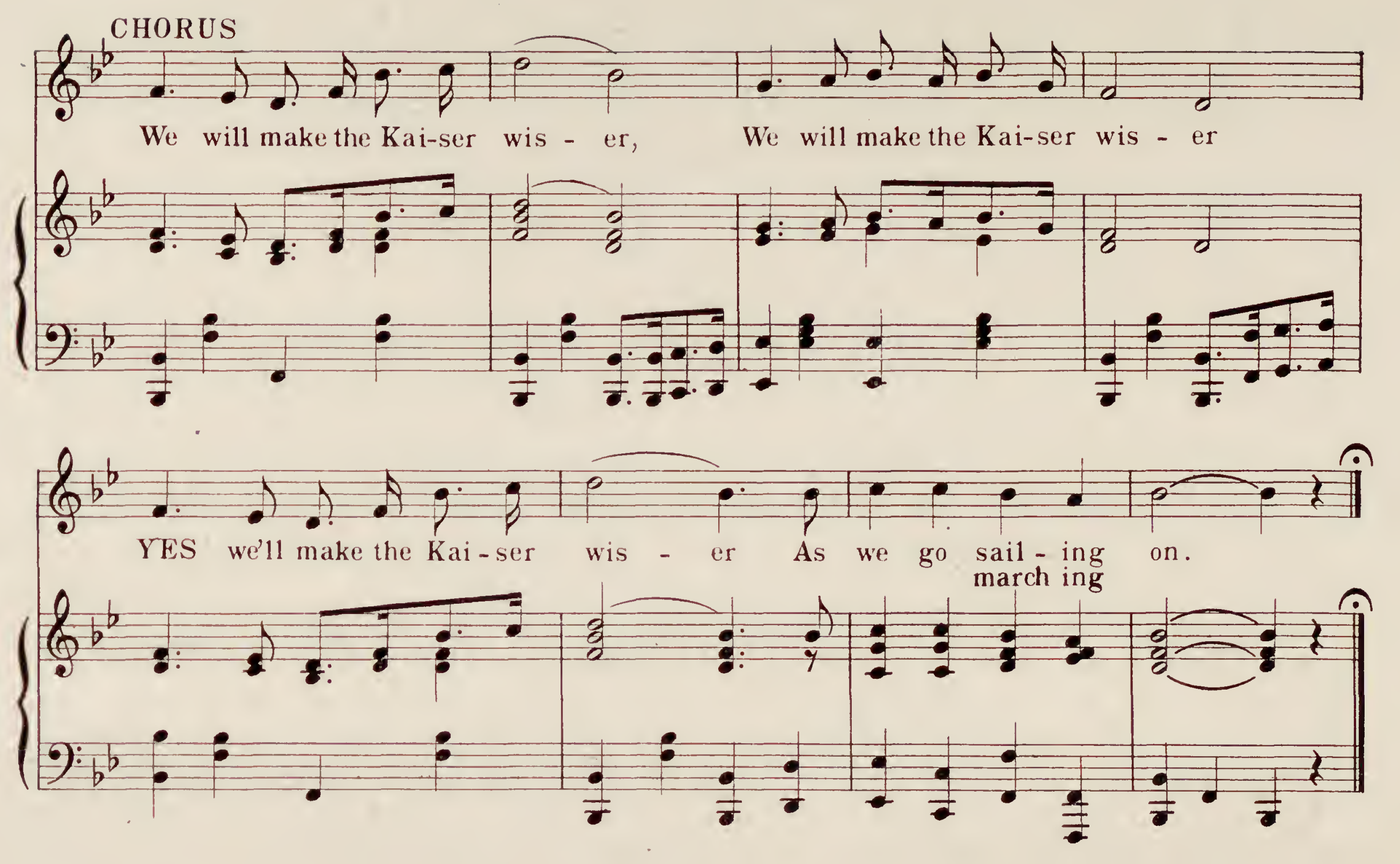

For many years he planned to fight, His slogan, Greed and Gain

The world is wrong and I am right imprinted on his Brain

U.S.A.has found the way, Yankee Doodle we will play

Cho. \{You bet your life, wéll make the Kaiser wiser

Dear Old France and Johnny Bull with Belgium in the Lead

Checked the beast when he was full of military speed

When he was sure he'd won the day your Uncle Sam got in the fray

Cho. \{To help to make the German Kaiser wiser

He realized we had his Goat in any fair play fight

Then under cover the old U-boat came stealing in the night

But, Yankee brains still shrewd and keen will put a crimp in Submarine

Cho. WW're on the job to make the Kaiser wiser.

Then came Zepplein floating high, the German's pride and joy

Dropping bombs and playing spy, this weakling, wind-bag toy

French and English birds were made, that knocked the wind-bag in the shade

Cho. United States will fly till Kaiser's wiser.

Now let every Chick and Child with courage in his soul

Help to cage this beast so wild and drive him in his hole

Old Glory is the winning card for us to play in his back yard

Cho. We're in to win and make the Kaiser wiser. 
Another recent Successful Song published by Sumner and Maher

\section{Somewhere in France}

Poem by

MABEL GREGG.
Melody by

J. STAFFORD SUMNER.

REFRAIN.
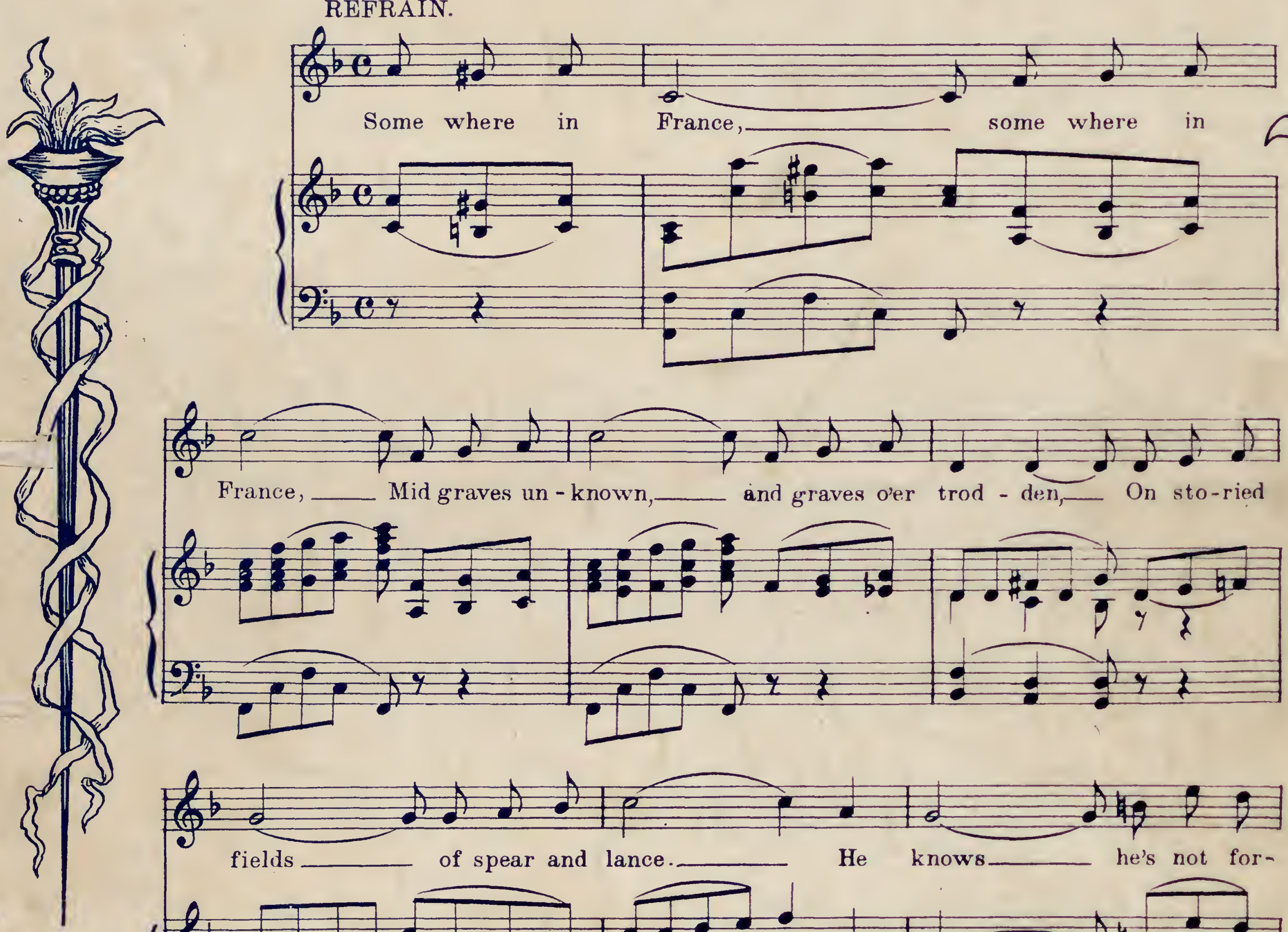

Some where in France,

some where in

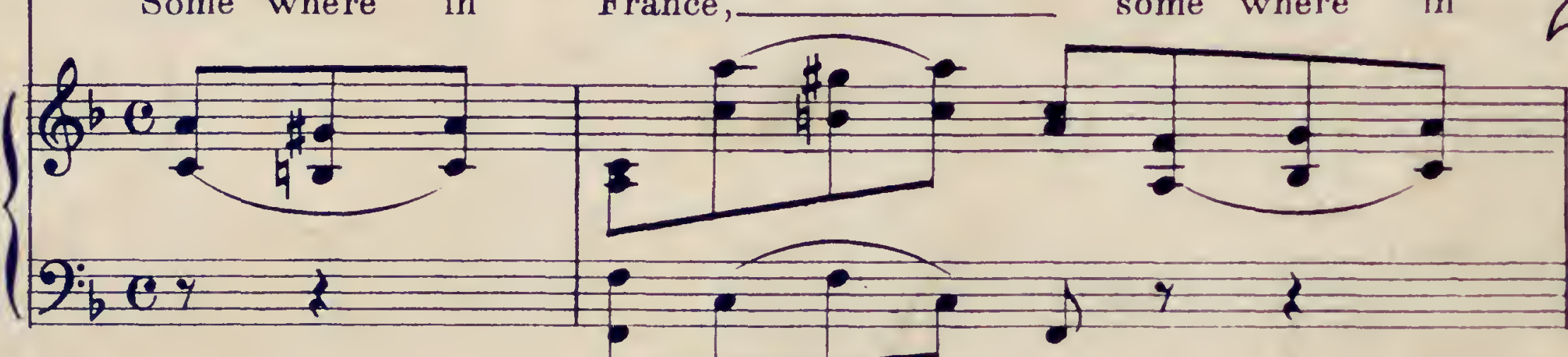

(

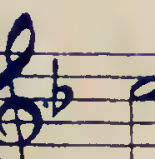
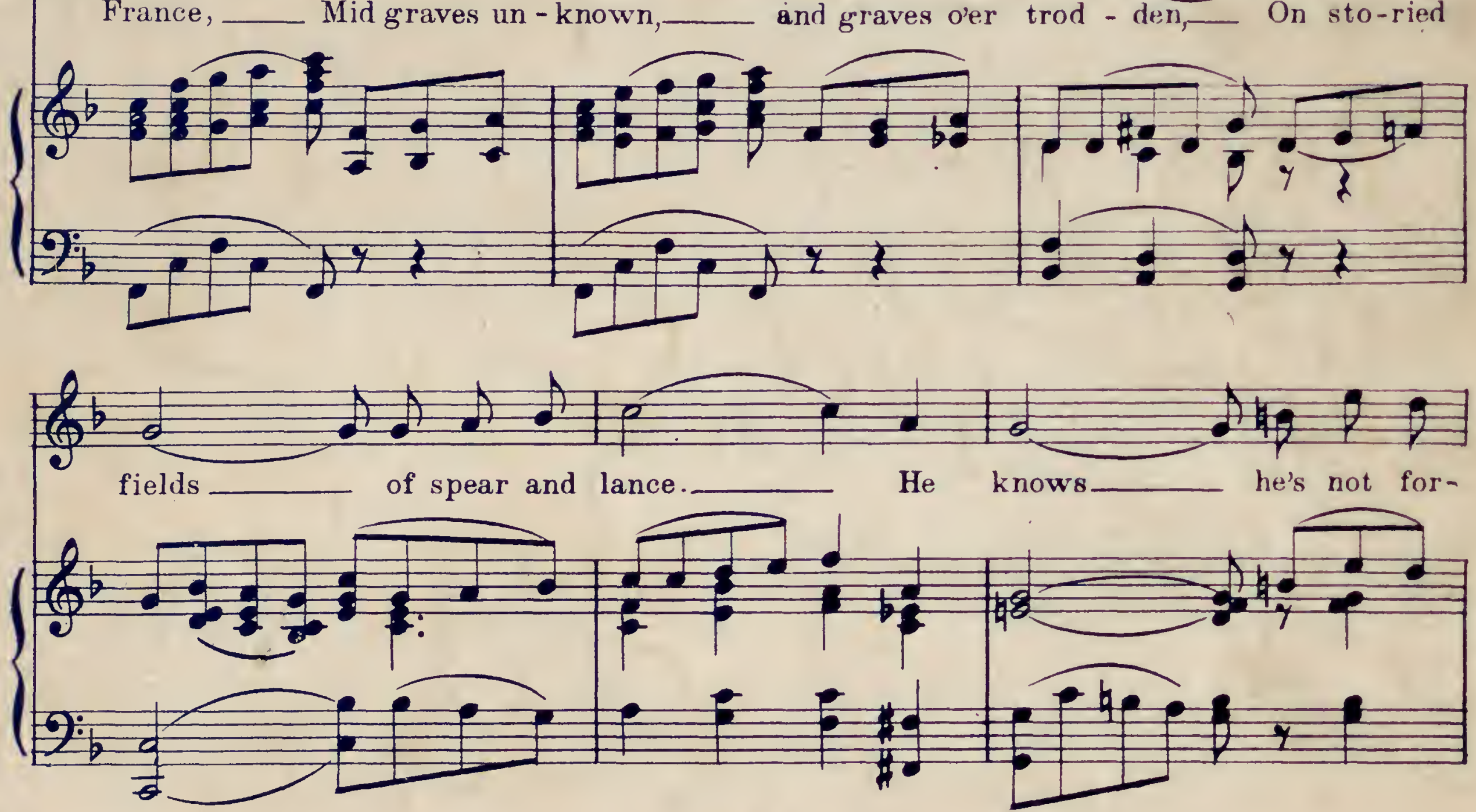

SUMNER and MAHER PUBLISHING CO.

Lyon and Healy Bldg., Chicago,Ill. 